\title{
The mediating effect of knowledge sharing between organisational culture and turnover intentions of professional nurses
}

\author{
Authors: \\ Everd J. Jacobs ${ }^{1}$ \\ Gert Roodt ${ }^{1}$ \\ Affiliations: \\ ${ }^{1}$ Department of Industrial \\ Psychology and People \\ Management, University of \\ Johannesburg, South Africa \\ Correspondence to: \\ Everd Jacobs \\ Email: \\ ejacobs@solplaatje.org.za \\ Postal address: \\ Private Bag X5030, \\ Kimberley 8300, \\ South Africa \\ Dates: \\ Received: 25 May 2010 \\ Accepted: 30 Nov. 2010 \\ Published: 02 Mar. 2011 \\ How to cite this article: \\ Jacobs, E.J. \& Roodt, G., \\ 2011, 'The mediating effect \\ of knowledge sharing \\ between organisational \\ culture and turnover \\ intentions of professional \\ nurses ', SA Journal of \\ Information Management \\ 13(1), Art. \#425, 6 pages. \\ doi:10.4102/sajim. \\ v13i1.425
}

(C) 2011. The Authors Licensee: OpenJournals Publishing. This work is licensed under the Creative Commons Attribution License.
Professional nurses routinely use highly developed domain knowledge in combination with experiential knowledge to deliver quality care. However, this knowledge is often lost to employers as the migration of professional nurses from the developing countries to the developed world has become a global problem. The objective of this study therefore was to determine the relationships between organisational culture, knowledge sharing and turnover intentions and thereafter to propose knowledge sharing as a mediating variable in this relationship in order to suggest a retention strategy. A cross-sectional field survey design with questionnaires was used on a sample of professional nurses $(N=530)$ in private and provincial hospitals in South Africa. The tri-variate procedure of Baron and Kenny for mediation testing was adopted. The results indicated that a positive correlation exists between organisational culture and knowledge sharing, but a significant negative correlation between organisational culture and turnover intentions, as well as between knowledge sharing and turnover intentions. Finally, the results indicated that knowledge sharing mediates the relationship between organisational culture and turnover intentions, although with a small effect size. The findings suggest that turnover intentions of nurses can be actively managed through contextual variables such as organisational culture and opportunities for knowledge sharing.

\section{Introduction}

South Africa's well trained professional nurses are a sought-after resource in high-paying industrial countries; this exodus will have a catastrophic effect on the delivery of health care over the next decade (Brits 2003; Ramadikela 2003). A few factors make the retention of professional nurses almost uncontrollable for nursing employers in South Africa (Kockott 2003):

- financial constraints to compete with remuneration offerings from international competitors

- current exchange rates to earn foreign money

- tax-free salaries.

However, it is suggested in this article that individuals do not become committed to an organisation by virtue of financial incentives only. Rather, individuals enter an organisation with certain needs, desires and skills and expect to find a work environment in which they can utilise their abilities and satisfy many of their needs, such as sharing and enhancing their knowledge (Lum, Kervin, Clark, Reid \& Sirola 1998). The importance of knowledge management in a contextual setting is essential to this argument.

It is reported, although not yet empirically determined, that organisational culture in hospitals can contribute towards lower turnover (Coile 2001; Waldman, Smith \& Hood 2003). It is also suggested in this article that knowledge sharing behaviour affect turnover intentions. There has been a growing acknowledgement that much organisational knowledge is tacit in nature, meaning it resides in the minds and experiences of people (Hislop 2003; Rowley 2003). Knowledge sharing occurs when an individual is willing to assist as well as learn from others in the development of new competencies (Rowley 2003). Very little research focused on knowledge sharing as a psychological need of people as well as the development of constructs to measure knowledge sharing and possible outcomes (Hislop 2003).

It is therefore postulated in this article that organisational culture will facilitate a positive attitude towards knowledge sharing and that the opportunities and challenges to fulfill the needs associated with knowledge sharing, will be so rewarding that people will be inclined to stay with the organisation. If this is true, employers will know which aspects of organisational culture predict lower intentions to quit and can embark on strategies around knowledge sharing activities to retain their talent. 
A short literature overview of the three variables is discussed next. Special emphasis is placed on knowledge sharing as proposed mediating variable in this article and will therefore receive special attention in the theoretical overview and the development of a knowledge sharing construct.

\section{Organisational culture}

Organisational culture can be introduced as a set of values, beliefs and behaviour patterns that form the core identity of organisations and help in shaping the employees' behaviour (Van der Post, de Coning \& Smit 1997). The study of organisational culture can be approached by identifying certain dimensions that shape behaviour and eventually can be regarded as the culture of the organisation. The dimensions include the following:

- conflict resolution

- culture management

- customer orientation

- disposition towards change

- employee participation

- goal clarity

- human resource orientation

- identification with the organisation

- locus of authority

- management style

- organisational focus

- organisational integration

- performance orientation

- reward orientation

- task structure.

\section{Turnover intentions}

Turnover intentions are seen as a mental decision intervening between an individual's attitude regarding a job and the stay or leave decision and that can be regarded as an immediate antecedent to stay or to leave (Fox \& Fallon 2003). It has been successfully demonstrated in previous studies that behavioural intention to leave is consistently correlated with turnover and there is considerable support for the notion that intention to quit is probably the most important and immediate antecedent of turnover decisions (Fox \& Fallon 2003).

\section{Knowledge sharing}

Hislop (2003), who reviewed a significant number of studies in knowledge management, reported that these studies have a limited empirical basis and the majority can typically be described as 'exploratory studies', which illustrates the lack of depth in contemporary understanding of how human and social factors affect knowledge management and sharing initiatives. To date, much of the research of knowledge sharing focused on economic benefits such as being competitive (Gupta, Lyer \& Aronson 2000). Very little research focussed on knowledge sharing as a psychological need of people.
A common classification of organisational knowledge (Nonaka 1991) comprises explicit knowledge, which can be documented and shared and implicit or tacit knowledge, which resides in the minds, cultures and experiences within the organisation (Rowley 2003). Implicit or tacit knowledge includes the competence, experience and skills of employees. The management of tacit knowledge is primarily concerned with the management of the process of deriving value from knowledge. This is tightly coupled with processes such as training, learning, culture creation and knowledge sharing (Rowley 2003). Tacit knowledge is usually in the domain of subjective, cognitive and experiential learning. There has been a growing acknowledgement that much organisational knowledge is tacit in nature and for employers to benefit from their training and development programmes, there should be a willingness on the part of those workers who possess the necessary knowledge to share and communicate it (Hislop 2003).

In one of only a few quantitative empirical knowledge sharing studies reported in the literature, Ryu, Hee Ho and Han (2003) investigated knowledge sharing attitudes for physicians within hospitals. This study is of particular relevance as they operate in the same environment as professional nurses. Professional nurses routinely use highly developed domain knowledge in combination with experiential knowledge to deliver quality care. A limitation of this study was that it only measured physicians' readiness to share knowledge and did not focus on other contextual factors such as organisational culture.

\section{Research Design Research approach}

The research question will be investigated (tested) by making use of a field survey to obtain primary data. A survey can be described as a study that is usually quantitative in nature and which aims to provide a broad overview of a representative sample of a large population (Mouton 2001). The study can be described as ex-post facto research, meaning that a researcher does not have full control over the variables (as the problem already occurred), but at least medium control can be obtained through applying inferential statistics (De la Rey 1978; Mouton 2001). The study is correlational in nature as it tests for mediation. According to Smit (1995) the correlational design can be seen as the best controlled and precise non-experimental design. Individuals will form the target dimension. The population is literate and will therefore have the ability to complete the questionnaires.

The strengths of this design are that the potential exists to generalise to large populations if appropriate sampling design has been implemented; high measurement reliability if proper questionnaire construction was implemented and high construct validity if proper controls have been implemented (Mouton 2001). Researchers using this design should be careful of sampling error, questionnaire error, high refusal and non-response, data capturing error and 
inappropriate selection of statistical techniques (Mouton 2001). These issues were addressed as will be discussed in the following sections.

\section{Research sample}

The target population can be described as registered professional nurses working in hospitals. Staff (or assistant) nurses were not included in the target population. Various important challenges and problems had to be addressed to determine the sampling frame and unit of analysis. According to figures by the South African Nursing Council (in 2004), there were approximately 93000 registered professional nurses in South Africa (this figure must not be confused with the estimated 155400 if staff nurses are also taken into consideration). Professional nurses are employed in different sectors (e.g. hospitals, municipalities, academic institutions and other industries); however, hospitals are the most important employers of professional nurses. It was therefore decided to only include professional hospital nurses.

The next step was to select which hospitals to include in the sampling frame. It was decided to include in the sampling frame five private hospitals and four provincial (government) hospitals in three different regions (provinces). The motivation for this was based on the assumption that different types of hospitals (private and government) in different regions and surroundings (urban and rural) will probably have different organisational cultures that will yield a sample with diverse characteristics.

The next step was to decide on the actual composition of the unit of analysis (more or less 1100 professional nurses work in the selected hospitals). Although the target population was determined to the set criteria as explained, it was decided to make use of a non-probability (convenience) census-based survey at each of the selected hospitals. A non-probability sample in this sense could be described as involving all respondents from a population (professional nurses) who were available to complete the questionnaire at a specific point in time (normally a two day period) in the hospital.

The respondents were not randomly selected, but all who met the criteria and were available were included. The limitations compared to systematic or stratified sampling methods are acknowledged. Their weakness can to some extent be mitigated by using knowledge, expertise and care in selecting samples, as was the case in this study. It seemed practically and ethically correct to utilise a convenience sample as employers were reluctant to allow time off to complete the questionnaires due to staff shortages and the complex shift system that determine working hours for registered professional nurses, as well as the research procedure to personally visit hospitals to ensure a high response rate of questionnaires.

The final sample consists of 530 respondents in the selected hospitals (more or less $50 \%$ of the population). This resulted in a sample with diverse characteristics regarding race, age, home language, number of dependents, level of seniority, qualifications, tenure in hospital and profession, working in different units and gender. The completion of the questionnaires was personally administered and anonymously handled.

\section{Measuring instruments}

Organisational culture: The Organisational Culture Survey (Van der Post et al. 1997) was applied in this study to measure organisational culture. This 97 item instrument measures fifteen dimensions of organisational culture (e.g. conflict resolution, culture management, customer orientation). The questionnaire was factor analysed according to a procedure suggested in order to determine the factor structure of the instrument. One of the advantages of this method is to minimise artefactors. This procedure includes first and second level factor analysis (Schepers 2004; Schepers 1992). The questionnaire yielded a Cronbach alpha of 0.989 indicating acceptable reliability.

Knowledge sharing: A literature study was conducted to compile a questionnaire as no suitable measure for knowledge sharing was found. Based on this conceptual model, a questionnaire consisting of 23 items was developed (see Annexure A). Each item has a 5-point intensity response scale anchored at extreme poles ranging from 'to no extent' or 'disagree' (low intensity) to 'a large extent' or 'agree' (high intensity). An example of a question is: 'to what extent do you share knowledge in this organisation to get recognition?'

The questionnaire consists of six sections representing different domains of knowledge sharing, namely:

- why knowledge is shared in the organisation (e.g. to get recognition; 5 questions)

- opportunities for knowledge sharing (e.g. to attend training courses; 3 questions)

- the contribution of knowledge sharing to the organisation (e.g. competitiveness; 3 questions)

- why others readily share knowledge (e.g. that trust exists; 6 questions)

- why one would not readily share knowledge (e.g. career would be in danger; 3 questions)

- why others do not readily share knowledge (e.g. colleagues do not want to do likewise; 3 questions).

Next, a factor analysis was conducted on the knowledge sharing questionnaire. The purpose of a factor analysis is to cluster the items that measure a specific concept and to reject those that do not contribute in measuring the concept. The knowledge sharing questionnaire was factor analysed according to the procedure suggested by Schepers (2004) in order to determine the factor structure of the instrument. One of the advantages of this method is to minimise artefactors. This procedure includes first and second level factor analysis.

The first level factor analysis was based on the intercorrelation matrix of all items. The eigenvalues of the unreduced item intercorrelation matrix were calculated and it was suggested 
that five factors be extracted based on the eigenvalues greater than unity (Kaiser, 1970). A Principal axis factoring yielded five factors explaining about $66 \%$ of the variance in the factor space. This result supported the theoretical foundation of the construction of the original questionnaire as factor 1 was described by items 18-23 (the two sections that determine reasons why nurses do not want to share knowledge). Factor 2 was described by items 12-17 (reasons why others share knowledge), whilst factor 3 (items 1-5) consists of the questions that measure reasons why one should share knowledge. Factor 4 (items 9-11) determined opinions to what outcomes knowledge sharing can contribute to (e.g. competitiveness), whilst factor 5 (items 6-8) determined opportunities for knowledge sharing.

For the second level factor analysis, the subscores of the five factors (referred to earlier) were intercorrelated. Again, eigenvalues were calculated and two factors were postulated. These two factors were extracted by means of principal axis factoring. Factor 1 explains about $44 \%$ and factor two about $20 \%$ of the variance in the factor space. Factor 1 consists of items $6-8$ and $12-23$. This factor can be renamed as 'opportunities and pre-requisites to share and/or not to share'. Factor 2 consists of items 1-5 and 9-11 and can be renamed as 'expected personal and organizational outcomes'. The result obtained from the iterative reliability analysis of the knowledge sharing questionnaire yielded a Cronbach alpha of 0.839 for factor one and 0.838 for factor two, indicating an acceptable reliability. No items were rejected in both the first and second level factor analysis.

\section{Turnover intentions}

Turnover intentions were measured by an unpublished 14 item questionnaire (Jacobs \& Roodt 2004). The questionnaire was factor analysed and it yielded a Cronbach alpha of 0.839 indicating acceptable reliability.

\section{Statistical analysis}

The first objective was to determine the relationship between organisational culture, knowledge sharing and turnover intentions. This was tested by the Pearson productmoment correlation. The second objective was to test for mediation. Rather than only hypothesising a direct causal relationship between the independent variable and the dependent variable, a mediation model hypothesises that the independent variable causes the mediator variable, which in turn causes the dependent variable. The tri-variate approach for mediation testing of Baron and Kenny (1986) was applied to test for mediation. In general, a given variable may be said to function as a mediator to the extent that it accounts for the relation between the predictor and the criterion. To test for mediation one should estimate the following regression equations:

- regressing the mediator on the independent variable

- regressing the dependent variable on the independent variable

- regressing the dependent variable on both the independent variable and on the mediator.
Mediation holds if the combined regression of the independent variable (predictor) and mediator on the dependent variable (criterion) explain more variance than the predictor alone. Thereafter one should investigate the effect sizes of the partial Eta squared to provide an indication whether the mediation effect is small, medium or large. According to Baron and Kenny (1986), it is critical not only to examine the significance of the coefficients but also their absolute size.

\section{Results}

The Pearson moment coefficients indicated that a significant positive correlation exists between organisational culture and knowledge sharing $(r=0.558 ; p<0.01)$, but a significant negative correlation between organisational culture and turnover intentions $(r=-0.521 ; p<0,01)$ and knowledge sharing and turnover intentions $(r=0.418 ; p<0.01)$.

The first step in the mediation procedure is regressing the mediator (knowledge sharing) on the independent variable (organisational culture). Organisational culture explained $34 \%$ of the variance in knowledge sharing, thus supporting the first condition in the procedure to test mediation. The second step in testing for mediation is regressing the dependent variable (turnover intentions) on the independent variable (organisational culture). Organisational culture explained $27 \%$ of the variance in turnover intentions. The third step in testing for mediation is regressing the dependent variable on both the independent variable (organisational culture) and on the mediator (knowledge sharing). The independent variable (organisational culture) and mediator (knowledge sharing) explained almost $29 \%$ of the variance in turnover intentions. Since more variance is explained than by the independent variable alone (27\%) mediation holds.

According to Baron and Kenny (1986), it is critical not only to examine the significance of the coefficients but also their absolute size. Mediation holds if the effect of the independent variable on the dependent variable is less in the third equation than in the second equation $(0.140<0.271)$. Thus, knowledge sharing is a mediating variable albeit with a small effect size (0.027; Eta squared-rooted $=0.164)$. The following criteria were used to describe effect sizes:

- $\quad<0.1-$ no effect

- $0.1-0.3$ - small effect

- $0.3-0.5$ - medium effect

- 0.5 - large effect.

\section{Discussion}

This study contributed to a greater understanding of the importance of knowledge sharing in hospitals and amongst professional nurses by conducting a first and second level factor analysis as well as the tri-variate approach of Baron and Kenny to test for mediation. Firstly, the second level factor analysis clearly yielded the factor 'opportunities and pre-requisites to share and/or not to share'. This is 
a clear indication that knowledge sharing is the result of how nurses perceive their environment; it clearly indicates a huge responsibility on employers. Secondly, the second factor 'expected personal and organisational outcomes', indicates that nurses will share knowledge if they perceive desirable outcomes of their efforts. Furthermore, the significant negative relationship between knowledge sharing and turnover intentions clearly indicated that managers can indeed plan strategies and interventions to provide professional nurses with opportunities to share, including training courses, workshops and sharing in informal settings.

Knowledge sharing mediates the relationship between organisational culture and turnover intentions, although with a small effect size. However, it is clear that employers must create an organisational culture that is conducive to the pre-requisites necessary to ensure a willingness to share. The positive correlation between organisational culture and knowledge sharing clearly indicated the importance of organisational culture as a pre-requisite to share knowledge. It is recommended that nursing employers not only create opportunities to share, but also the incentives to learn and to study. The study provides evidence that in an 'electronic and computerised work environment' (explicit knowledge), the human being's 'perception towards knowledge sharing and capacity to share' (tacit knowledge) should not be neglected in order to understand knowledge management in its broader context.

Theoretically this study contributed to a better understanding of the importance of knowledge sharing behaviour in a contextual setting. It is recommended that knowledge sharing as theoretical and empirical concept needs further development and investigation, especially the development of knowledge sharing constructs should be a priority. The prerequisites (conditions) of knowledge sharing should also receive more attention. One possible line of thinking is to create experimental designs to measure direct causeeffect relationships of sharing behaviour and thereby control nuisance variables. It is furthermore suggested that if taken the consequences of the high turnover amongst nurses, more turnover models should be developed with different concepts such as organisational commitment, job satisfaction and organisational citizenship behaviours (OCB's) entered into the equation. The nursing population outside hospitals can also be involved in developing these models. Lastly, the importance of knowledge sharing as proposed in this study could be empirically tested in the health related environment for physicians, dentists, psychologists, medical rescue personnel, emergency services and laboratory technologists.

\section{References}

Baron, R.M. \& Kenny, D.A., 1986, 'The moderator-mediator variable distinction in social psychological research: Conceptual, strategic, and statistical considerations', Journal of Personality and Social Psychology 51(6), 1173-1182. doi:10.1037/00223514.51.6.1173, PMid:3806354

Brits, E., 2003, 'Te veel verpleërs land-uit, sê RGN ('Too many nurses leave country, says HSRC'), Die Burger, 2 July, p. 7.

Coile, R.C., 2001, 'Magnet hospitals use culture, not wages, to solve nursing shortage', Journal of Healthcare Management 46(4), 224-228. PMid:11482240

De la Rey, R.P., 1978, Statistiese metodes in sielkundige navorsing, Universiteit van Pretoria, Pretoria, Suid-Afrika.

Fox, S.R. \& Fallon, B.J., 2003., 'Modeling the effect of work/life balance on job satisfaction and turnover intentions', Paper presented at the 5th Australian Industrial and Organizational Psychology Conference, Melbourne, Australia, 2003.

Gupta, B., Lyer, L.S. \& Aronson, J.E., 2000, 'Knowledge management: practices and challenges', Industrial Management \& Data Systems 100(1), 17-21. doi:10.1108/02635570010273018

Hislop, D., 2003, 'Linking human resource management and knowledge management via commitment: A review and research agenda', Employee Relations 25(2),182-202. doi:10.1108/01425450310456479

Jacobs, E.J., \& Roodt, G., 2005, 'The development of a predictive model for turnover intentions of professional nurses' unpublished doctoral thesis, Dept. of Human Resource Management, University of Johannesburg.

Kaiser, H.F., 1970, 'A second-generation Little Jiffy', Psychometrika 35, 401-415. doi:10.1007/BF02291817

Kockott, F., 2003, 'Government developing strategies to retain health professionals', Business Day, 21 January, p. 3.

Lum, L., Kervin, J., Clark, K., Reid, F. \& Sirola, W., 1998, 'Explaining nursing turnover intent: Job satisfaction, Pay satisfaction, or Organizational commitment', Journal of Organizational Behaviour 19(3), 305-320. doi:10.1002/(SICI)10991379(199805)19:3<305::AID-JOB843>3.0.CO;2-N

Mouton, J., 2001, How to succeed in your master's and doctoral studies - A SouthAfrican guide and resource book, Van Schaik, Pretoria.

Nonaka, I., 1991, 'The knowledge creating company', Harvard Business Review 34(6), 96-114.

Ramadikela, N., 2003, 'Medical crisis looms in EC', Daily Dispatch, 24 September, p. 1.

Rowley, J., 2003, 'Knowledge management - the new librarianship? From custodians of history to gatekeepers to the future', Library Management 24(8), 433-440. doi:10.1108/01435120310501112

Ryu, S., Hee Ho, S. \& Han, I., 2003, 'Knowledge sharing behaviour of physicians in hospitals', Expert Systems with applications 25(1), 113-122. doi:10.1016/S09574174(03)00011-3

Schepers, J.M., 2004, 'Overcoming the effects of differential skewness of test items in scale construction', SA Journal of Industrial Psychology 30(4), 27-43.

Schepers, J.M., 1992, Toetskonstruksie: Teorie en praktyk (Test construction: Theory and Practice). RAU Drukpers, Johannesburg.

Smit, G.J., 1995, Navorsingsmetodes in die Gedragswetenskappe. Opvoedkundige Uitgewers, Pretoria.

Van der Post, W.Z., de Coning, T.J. \& Smit, E.V., 1997, 'An instrument to measure organizational culture', South African Journal of Business Management 28(4), 147-168.

Waldman, J.D., Smith, H.L. \& Hood, J.N., 2003, 'Corporate Culture: The missing piece of the healthcare puzzle', Hospital topics 81(1), 5-16. doi:10.1080/00185860309598010, PMid:14513744

Annexure A: Knowledge Sharing Questionnaire. The following questionnaire measures your perceptions about knowledge sharing in your organization. You are requested to cross (x) or circle (o) the number of your choice which most accurately fits the extent to which you evaluate the organization in which you work. After you have read each question, please decide the degree to which your answer accurately describes your own situation and your feelings, using the following scale:

\begin{tabular}{|c|c|c|c|c|c|c|c|}
\hline \multirow{2}{*}{$\begin{array}{l}\text { Example: To what extent do you share knowledge in this organisation ... } \\
\text { Answer: } 1 \text {. to get recognition? }\end{array}$} & \multicolumn{4}{|c|}{$\longleftarrow$ Lower } & \multicolumn{3}{|c|}{ Higher $\longrightarrow$} \\
\hline & To no extent & 1 & 2 & 3 & 4 & (5) & To a large extent \\
\hline \multicolumn{8}{|l|}{ 1. To what extent do you share knowledge in this organisation ... } \\
\hline 1.1. to get recognition? & To no extent & 1 & 2 & 3 & 4 & 5 & To a large extent \\
\hline 1.2. to be rewarded? & To no extent & 1 & 2 & 3 & 4 & 5 & To a large extent \\
\hline 1.3. to satisfy your self-fulfillment needs? & To no extent & 1 & 2 & 3 & 4 & 5 & To a large extent \\
\hline 1.4. to support management strategic objectives? & To no extent & 1 & 2 & 3 & 4 & 5 & To a large extent \\
\hline 1.5. to enhance your career? & To no extent & 1 & 2 & 3 & 4 & 5 & To a large extent \\
\hline
\end{tabular}


Annexure A CONTINUES: Knowledge Sharing Questionnaire. The following questionnaire measures your perceptions about knowledge sharing in your organization. You are requested to cross (x) or circle (o) the number of your choice which most accurately fits the extent to which you evaluate the organization in which you work. After you have read each question, please decide the degree to which your answer accurately describes your own situation and your feelings, using the following scale:

\begin{tabular}{|c|c|c|c|c|c|c|c|}
\hline \multirow{2}{*}{$\begin{array}{l}\text { Example: To what extent do you share knowledge in this organisation ... } \\
\text { Answer: } 1 \text {. to get recognition? }\end{array}$} & \multicolumn{4}{|c|}{$\longleftrightarrow$ Lower } & \multicolumn{3}{|c|}{ Higher $\longrightarrow$} \\
\hline & To no extent & 1 & 2 & 3 & 4 & (5) & To a large extent \\
\hline \multicolumn{8}{|l|}{ 2. How often do you have the opportunity ... } \\
\hline 2.1. to attend training courses? & Never & 1 & 2 & 3 & 4 & 5 & Most of the times \\
\hline 2.2. to share your knowledge with colleagues? & Never & 1 & 2 & 3 & 4 & 5 & Most of the times \\
\hline 2.3. to attend informal gatherings where knowledge is shared? & Never & 1 & 2 & 3 & 4 & 5 & Most of the times \\
\hline \multicolumn{8}{|l|}{ 3. How much do you agree that knowledge sharing contributes to... } \\
\hline 3.1. the success of this organisation? & Disagree & 1 & 2 & 3 & 4 & 5 & Agree \\
\hline 3.2. the competitiveness of this organisation? & Disagree & 1 & 2 & 3 & 4 & 5 & Agree \\
\hline 3.3. the innovativeness of this organisation? & Disagree & 1 & 2 & 3 & 4 & 5 & Agree \\
\hline \multicolumn{8}{|l|}{$\begin{array}{l}\text { 4. To what extent do you experience that others share knowledge due to the } \\
\text { following reasons... }\end{array}$} \\
\hline 4.1. trust that exists in the organisation? & To no extent & 1 & 2 & 3 & 4 & 5 & To a large extent \\
\hline 4.2. the likelihood that colleagues will do likewise? & To no extent & 1 & 2 & 3 & 4 & 5 & To a large extent \\
\hline 4.3. it is highly valued by management? & To no extent & 1 & 2 & 3 & 4 & 5 & To a large extent \\
\hline 4.4. the organisational culture facilitates a learning environment? & To no extent & 1 & 2 & 3 & 4 & 5 & To a large extent \\
\hline 4.5. people who share knowledge are regarded as experts? & To no extent & 1 & 2 & 3 & 4 & 5 & To a large extent \\
\hline 4.6. it contributes to positive performance appraisals? & To no extent & 1 & 2 & 3 & 4 & 5 & To a large extent \\
\hline \multicolumn{8}{|l|}{$\begin{array}{l}\text { 5. To what extent you do not readily share knowledge due to the following } \\
\text { reasons ... }\end{array}$} \\
\hline 5.1. you are afraid your career would be in danger if you make mistakes?(-) & To no extent & 1 & 2 & 3 & 4 & 5 & To a large extent \\
\hline 5.2. not enough trust exists in this organisation? (-) & To no extent & 1 & 2 & 3 & 4 & 5 & To a large extent \\
\hline 5.3. others don't want to do likewise? (-) & To no extent & 1 & 2 & 3 & 4 & 5 & To a large extent \\
\hline \multicolumn{8}{|l|}{$\begin{array}{l}\text { 6. To what extent do you experience that others do not readily share } \\
\text { knowledge due to the following reasons ... }\end{array}$} \\
\hline 6.1. they are afraid their careers would be in danger if they make mistakes? (-) & To no extent & 1 & 2 & 3 & 4 & 5 & To a large extent \\
\hline 6.2. not enough trust exist in this organisation? (-) & To no extent & 1 & 2 & 3 & 4 & 5 & To a large extent \\
\hline 6.3. colleagues don't want to do likewise? (-) & To no extent & 1 & 2 & 3 & 4 & 5 & To a large extent \\
\hline
\end{tabular}

